\title{
Kemampuan Komunikasi Matematis Siswa Terhadap Materi Persamaan Linear Satu Variabel
}

\author{
Nurapni Sopia ${ }^{1, \text { a) }}$, Kurniawati ${ }^{2, \text { b) }}$ \\ ${ }^{123}$ Program Studi Pendidikan Matematika STKIP Persada Khatulistiwa Sintang \\ Email penulis: ${ }^{\text {a) }}$ nurapni22sopia@gmail.com, ${ }^{\text {b) }}$ kurniawatinong@gmail.com
}

\begin{abstract}
This study aims to describe the mathematical communication skills of junior high school students class VII B at SMP N 3 Sungai Tebelian, Sintang, West Kalimantan. In addition, to examine the communication problems faced by students during learning on the One Variable Linear Equation material. The research method used is the description method with the research subject of 25 students. This research instrument uses a response questionnaire to determine students' mathematical communication skills with 12 questions that are distributed directly via offline. There are six indicators of mathematical communication skills analyzed but only one indicator can be achieved with the percentage of student questionnaire results obtained $3.5 \%$.
\end{abstract}

Keywords: Analysis, Mathematical Communication, One Variable Linear Equation.

\begin{abstract}
Abstrak
Penelitian ini bertujuan untuk mendeskripsikan kemampuan komunikasi matematis siswa SMP kelas VII B di SMP N 3 Sungai Tebelian, Sintang, Kalimantan Barat. Selain itu, untuk menelaah masalah-masalah komunikasi yang dihadapi siswa selama pembelajaran pada materi Persamaan Linear Satu Variabel. Adapun metode penelitian yang digunakan adalah metode deskripsi dengan subjek penelitian 25 siswa. Instrumen penelitian ini menggunakan angket respon untuk mengetahui kemampuan komunikasi matematis siswa dengan 12 butir pertanyaan yang disebarkan secara langsung melalui offline. Ada enam indikator kemampuan komunikasi matematis yang dianalisis namun hanya satu indikator yang dapat dicapai dengan presentase perolehan hasil angket siswa $3,5 \%$.
\end{abstract}

Kata kunci: Analisis, Komunikasi Matematis, Persamaan Linear Satu Variabel.

Copyright (c) 2021 Sopia, Kurniawati

$\triangle$ Corresponding author:

Email Address: nurapni22sopia@gmail.com

Received 3 Agustus 2021, Accepted 3 Agustus 2021, Published 20 Agustus 2021

https://doi.org/10.21009/jrpmj.v3i2.22261

\section{PENDAHULUAN}

Pendidikan memiliki peranan yang sangat penting bagi setiap manusia dan sumber daya manusia yang tersebar disetiap bagian pelosok Indonesia. Tujuan utama pendidikan nasional Indonesia yaitu "mencerdaskan kehidupan bangsa," seperti yang termuat dalam UUD 1945. Agar tujuan dari pendidikan nasional tersebut dapat terwujud, maka pemerintah mewajibkan seluruh tingkatan sekolah mengadakan proses pembelajaran untuk setiap mata pelajaran, Salah satu mata pelajaran tersebut adalah matematika yang merupakan pelajaran pokok yang harus diterapkan dalam pendidikan formal tingkat dasar hingga perguruan tinggi. Tujuan pembelajaran matematika satu diantaranya yaitu agar siswa dapat mengkomunikasikan gagasan matematika dengan menggunakan simbol, grafik, tabel dan diagram atau hal lain yang dapat memperjelas suatu permasalahan(Mulligan, 2015; NCTM, 2000; Paridjo \& Waluya, 2017). 
Oleh sebab itu, melalui mata pelajaran matematika, maka dapat tercapai kemampuan berpikir yang kritis, logis, kreatif, sistematis, dan bisa bekerja sama sehingga mampu untuk menghadapi berbagai tantangan yang muncul dalam kehidupan masyarakat(Ku, 2009; Octaviani et al., 2021; Susanti \& Hartono, 2019). Matematika merupakan pelajaran pokok yang harus diajarkan dalam pendidikan formal tingkat dasar dan menengah karena dianggap pelajaran yang essensial. Satu diantara tujuan diberikannya matematika, yaitu agar siswa dapat mengkomunikasikan gagasan matematika dengan simbol, grafik, tabel, dan diagram atau hal lain untuk memperjelas masalah. Dalam pembelajaran matematika terdapat hal penting yang harus diperhatikan yaitu komunikasi dalam proses pembelajaran tersebut." Dalam menguasai pembelajaran metematika paling tidak siswa harus memiliki kemampuan komuniksi matematis yang baik dan inovatif(Radford, 2008; Winardi et al., 2019). Dengan melakukan komunikasi pada pembelajaran matematika siswa dapat menumbuhkan dan mengembangkan kegiatan berpikir secara matematis, karena kegiatan komunikasi dalam pembelajaran metematika dapat memfasilitasi siswa untuk mengembangkan cara berpikir secara matematis(Hastuti et al., 2021; Samo, 2017). Kemampuan komunikasi matematis memiliki kolerasi yang sangat erat dengan proses-proses pembelajaran matematika yang lainnya, seperti pada kegiatan pemecahan masalah, melakukan representasi, mengemukakan argument, melakukan pembuktian, menghubungkan nalar dam argument(Rahmi, 2021; Rellensmann et al., 2017). Dalam mengkomunikasikan pemikiran matematis, siswa diharapkan untuk memahami konsep dari pemikiran yang siswa hasilkan kemudian dapat dikomunikasikan dengan baik agar dapat menghasilkan penyelesaikan melalui solusi yang disampaikan oleh suatu solusi yang dipakai dalam kegiatan memecahkan suatu masalah atau hambatan dalam proses pembelajaran yaitu dapat dilakukan dengan cara mengidentifikasi masalah yang sedang dihadapi(Kosiret et al., 2021; Sriraman \& English, 2005).

Berjalan dari pendapat yang telah dipaparkan dengan memahami konsep-konsep tersebut siswa dapat terarah untuk melakukan beberapa hal, sebagai berikut; pertama, melalui kegiatan diskusi siswa dapat saling mengkomunikasikan gagasan-gagasan atau ide-ide yang dihasilkan melalui kegiatan berpikir sistematis(Sommerhoff \& Ufer, 2019). Kedua, dalam kegiatan diskusi selain mengkomunikasikan gagasan-gagasan dan ide-ide yang dihasilkan, secara refleksi dan sistematis siswa yang belum menemukan ide-ide atau gagasan-gagasan dapat menemukan permasalahan dalam diskusi tersebut. Siswa disarankan untuk mencatat ide-ide atau dalam diskusi untuk menindaklanjuti pelatihan daya ingat matematis siswa agar pada kegiatan diskusi selanjutnya siswa dapat secara refleksi melakukan berpikir secara sistematis. Terakhir, melalui kegiatan diskusi tersebut, siswa mampu mengembangkan konsep-konsep dalam komunikasi matematis baik dalam penyampaian gagasangagasan atau ide-ide maupun dalam mengembangkan kemampuan untuk memecahkan masalah(Maulidiya et al., 2018).

Namun kenyataan di lapangan siswa mengalami kesulitan dalam memahami konsep-konsep dari pemikiran untuk menemukan solusi yang tepat dan siswa keliru dalam melakukan penyelesaian atas permasalahan dalam pembelajaran metematika karena pada saat mengkomunikasikan konsep- 
konsep dan solusi yang dikemukakan siswa belum mampu menggunakan bahasa matematis yang tepat. Hal ini disedababkan sebagian besar siswa kurang memperhatikan guru, kurang tenang dan ribut sendiri ketika pembelajaran dilakukan, kurang termotivasi dan mengganggu teman yang lainnya, dan ada pula siswa yang mengantuk pada saat proses belajar mengajar pada kelas VII B SMP N 3 Sungai Tebelian.

Oleh karena itu, berdasarkan latar belakang yang telah diuraikan peneliti ingin mendeskripsikan "Kemampuan Komunikasi Matematis Siswa Terhadap Materi Persamaan Linear Satu Variabel Pada Siswa Kelas VII B SMP Negeri 3 Sungai Tebelian semester genap Tahun pembelajaran 2021/2022.

\section{METODE}

Metode yang digunakan dalam penelitian ini adalah metode kualitatif yakni menghasilkan uraian data baik yang berupa kata-kata dalam bentuk tertulis maupun secara lisan dari orang-orang (sumber) dan beberapa tindakan dilapangan yang dapat dianalisis, penelitian ini menggunakan metode kualitatif untuk mengetahui baik secara detail, mendalam dan berkolaborasi atas komunikasi matematis siswa saat proses pembelajaran metematika pada materi persamaan linear satu variable. Penelitian ini dilakukan secara langsung dilapangan dengan cara mengamati, mendata, mewawacara, dan berdasarkan sumber yang mengemukakan tentang komunikasi matematis dalam pembelajan matematika pada pada materi persamaan linear satu variable. Hasil yang diperoleh dari penelitian tersebut disusun segera pada saat itu juga, dan data yang dikumpulkan melalui pengamatan, wawancara, rekaman, pemotretan atau dokumentasi dan catatan yang dihasilkan dalam kegiatan lapangan saja yang tidak disusun dalam format angka-angka. Namun, hasil analisi data yang berupa deskripsi secara detail yang disajikan dalam bentuk uraian naratif. Keistimewaan dari pemaparan data ini pada umumnya untuk menjawab pertanyaan bagaimanakah cara mendeskripsikan komunikasi matematis siswa yang mengikuti pembelajaran matematika pada materi persamaan linear satu variable. Bentuk penelitian yang digunakan adalah bentuk penelitian deskriptif. Penelitian deskriptif ini biasa digunakan untuk menganalisis kejadian, fenomena atau keadaan secara sosial. Adapun tempat pada penelitian ini yaitu di SMP N 3 Sungai Tebelian yang terletak di tengah pusat Kecamatan Tebelian Kabupaten Sintang. Adapun waktu pelaksanaan pada penelitian ini yaitu pada Tahun Pelajaran 2021/2022 Semester dua di SMP N 3 Sungai Tebelian kelas VII B yang berjumlah 32 siswa.

\section{HASIL DAN PEMBAHASAN}

Penelitian ini dilaksanakan di Sekolah Menengah Pertama (SMP) N 3 Sungai Tebelian pada tahun ajaran 2021/2022. SMP N 3 Sungai Tebelian terletak di Kecamatan Tebelian Kabupaten Sintang. Bentuk gedung SMP N 3 Sungai Tebelian berbentuk U yang terdiri kantor guru, kantor kepala sekolah, kantor tata usaha (TU), kelas VII A, B, C, kelas VIII A, B, C, kelas IX A, B, C, D, perpustkaan, lap komputer, ruang UKS, serrta WC guru, siswa putra dan siswa putri. Adapun tenaga pendidik dan staf 
di SMP N 3 Sungai Tebelian yaitu berjumlah 12 orang yang terdiri dari Kepala Sekolah, Wakil Kepala Sekolah Bidang Kurikulum, Wakil Kepaka Sekolah Bidang Kesiswaan, 1 orang Guru Pendidikan Jasmani Olahraga dan Kebugaran, 1 orang Guru IPS, 1 orang Guru Agama Kristen Protestan, 2 orang Guru IPA, 1 orang Guru PKN, 1 orang Guru Agama Islam, 1 orang Guru Agama Khatolik. Latar sosial ekonomi kehidupan yang dimiliki oleh orang tua siswa disekolah tersebut beragam, seperti PNS, Swasta, petani dan lain sebagainya. Sebelum melaksanakan penelitian, terlebih dahulu dilakukan beberapa persiapan yang mendukung pelaksanakan penelitian agar penelitain yang dilakukan bisa berjalan dengan baik. Persiapan tersebut diawali setelah melakukan seminar peneliti mengubah variabel judul penelitian dan konfirmasi kepada dosen pembimbing, dilanjutkan dengan validasi instrument lembar wawancara, dan validasi lembar pedoman observasi, kemudian meminta surat izin penelitian kepada Kaprodi Pendidikan Matematika, mempersiapkan istrumen atau alat bantu yang akan digunakan dalam pengumpulan data, meminta izin kepada kepala sekolah untuk malakukan penelitian disekolah tersebut, melakukan pendekatan dengan guru kelas VII dan guru mata pelajaran matematika yang akan dilibatkan dalam pengumpulan data, dan melaksanakan tindakan pengumpulan data dengan alat atau instrument yang telah disiapkan.

Berikutnya pelaksanaan penelitian ini mulai dari peneliti dating ke SMP N 3 Sungai Tebelian berdasarkan perjanjian dengan pihak sekolah dan guru matematika kelas VII B untuk meminta datadata dan dokumentasi dari sekolah seperti penyebaran angket respon kepada siswa kelas VII B. Pada tanggal 5 Juni 2021 peneliti melaksanakan penelitian di SMP N 3 Sungai Tebelian. Pada tanggal 7 Juni 2021 peneliti datang ke lokasi penelitian untuk menyerahkan surat izin penelitian kepada kepala sekolah dan diketahui oleh para guru. Pada hari yang sama peneliti juga melaksanakan wawancara dengan guru matematika untuk bertanya tentang komunikasi matematis siswa kelas VII B terhadap materi persamaan linear satu variabel. Pada hari yang sama tenggal 7 Juni 2021 mendapatkan izin dari sekolah untuk melakukan penelitian di SMP N 3 Sungai Tebelian. Pada tanggal 11 Juni 2021 peneliti melakukan penelitian dengan menyebarkan angket respon kepada siswa kelas VII B untuk mengukur tingkat kemampuan komunikasi matematis siswa terhadap materi persamaan linear satu variabel, dipandu oleh guru mata pelajaaran matematika yang sekaligus merupakan wali kelas VII dan beberapa guru lainnya.

Selanjutnya, setelah semua data terkumpul maka pada tanggal 14 Juni 2021 peneliti memberi tahu kepada kepala sekolah dan wali kelas VII B serta guru-guru lainnya bahwa penelitian yang peneliti laksanakan di SMP N 3 Sungai Tebelian sudah selesai. Setelah penelitian selesai, kepala sekolah memberi surat keterangan atau surat balasan izin penelitian bahwa peneliti telah selesai melakukan penelitian di SMP N 3 Sungai Tebelian. Setelah selesai melaksanakan penelitian serta kepala sekolah juga telah memberikan surat keterangan telah melakukan penelitian. Maka tahap berikutnya adalah pengecekan dan pemeriksaan keabsahan data. Pada tahap pengecekan dan pemeriksaan keabsahan data dengan informasi yang di dapat dari narasumber serta dokumen yang digunakan untuk membuktikan keabsahan data yang diperoleh. Pada tahap ini juga dilakukan penyederhanaan data di temukan dilapangan agar dalam pelaporan penelitian tidak diragukan lagi keabsahannya. 
Untuk mengetahui kemampuan komunikasi matematis siswa, peneliti menggunakan pedoman wawancara yang dilakukan terhadap siswa. Adapun hasil wawancara yang diperoleh peneliti dari responden adalah sebagai berikut: dari hasil wawancara peneliti mengambil 2 orang siswa dari keseluruhan 32 siswa kelas VII B. Siswa yang memiliki kemampuan tinggi dan siswa yang memiliki kemampuan kurang, dari hasil wawancara dapat disimpulkan bahwa siswa yang memiliki kemampuan komunikasi matematis tinggi mengungkapkan bahwa kemampuan matematisnya didukung oleh kecerdasan intelektualnya, motivasi yang baik dari keluarga dan orang tua, cara guru yang menyampaikan dalam mengajar sehingga semangat dalam mengikuti proses pembelajaran. Pada keenam indikator kemampuan komunikasi matematis siswa hampir semua dapat dikuasi meski ada sedikit kekeliruan, siswa yang memiliki kemampuan komunikasi matematis. Sedangkan kemampuan komunikasi matematis siswa yang kurang mengungkapkan bahwa yang menjadi masalah komunikasi matematisnya yaitu kurangnya motivasi yang diberikan oleh keluarga dan orang tua dalam pendidikannya, dan dari beberapa indikator kemampuan komunikasi matematis hanya beberapa aspek saja yang dapat dikuasi. Tujuannya adalah untuk melihat bagaimana respon siswa terhadap komunikasi matematis siswa. Siswa yang berprestasi tinggi/pandai yaitu siswa yang memiliki nilai akademis tinggi di kelas, sedangkan siswa yang termasuk dalam kategori kurang adalah siswa yang tidak menunjukkan prestasi di kelas dan tidak dapat mengikuti pembelajaran dengan baik. Alasan peneliti memilih dua kategori tersebut adalah untuk melihat kemampuan komunikasi matematis siswa selama kegiatan pembelajaran pada materi persamaan linear satu variabel yang telah dilaksanakan sebelumnya.

Data hasil angket siswa mengenai kemampuan komunikasi matematis siswa pada materi persamaan linear satu variabel diperoleh menggunakan angket terstruktur menggunakan jawaban tertutup. Angket tertutup dengan jawaban tertutup artinya yaitu setiap pertanyaan angket telah memiliki alternative jawaban. Adapun alternative jawaban yang disediakan dalam angket tertutup pada penelitian ini adalah Ya (Y) dan Tidak (T). Hasil angket menunjukkan bahwa kemampuan komunikasi matematis siswa pada materi persamaan linear satu variabel siswa kelas VII B SMP N 3 Sungai Tebelian masuk dalam ketegori baik, yang artinya siswa kelas VII B telah mengikuti pembelajaran dengan baik dan sudah mampu melaksanakan indicator-indikator dalam kemampuan komunikasi matematis.

Tabel 1. Perolehan Angket Kemampuan Komunikasi Matematis Siswa

\begin{tabular}{llc}
\hline \multicolumn{1}{c}{$\begin{array}{c}\text { Standar Indikatir Kemampuan Komunikasi } \\
\text { Matematis }\end{array}$} & $\begin{array}{c}\text { Nomor } \\
\text { Item }\end{array}$ & $\begin{array}{c}\text { Skor } \\
\text { perolehan }\end{array}$ \\
\hline $\begin{array}{l}\text { Mengungkapkan dan menjelaskan pemikiran siswa tentang ide } \\
\text { matematika dan hubungannya. }\end{array}$ & 1,7 & $2,5 \%$ \\
\hline $\begin{array}{l}\text { Merumuskan definisi matematika dan membuat generalisasi } \\
\text { yang diperoleh melalui investigasi } \\
\text { (penemuan). }\end{array}$ & 2,12, & $-2,66 \%$ \\
\hline $\begin{array}{l}\text { Mengungkapkan ide matematika secara lisan dan tulisan } \\
\text { Membaca wacana matematika dengan pemahaman. }\end{array}$ & 3,4, & $3,5 \%$ \\
\hline
\end{tabular}




\begin{tabular}{lll}
\hline $\begin{array}{l}\text { Menjelaskan dan mengajukan serta memperluas pertanyaan } \\
\text { terhadap matematika yang telah dipelajarinya. }\end{array}$ & $-1,33 \%$ \\
\hline $\begin{array}{l}\text { Menghargai keindahan dan kekuatan notasi matematika, serta } \\
\text { perannya dalam mengembangkan ide atau gagasan matematika. }\end{array}, 11$ & $-4.83 \%$ \\
\hline
\end{tabular}

Berdasarkan Tabel 1 menunjukkan bahwa perolehan nilai perolehan tertinggi untuk indikator kemampuan komunikasi matematis siswa terletak pada indiator mengungkapkan ide matematika secara lisan dan tulisan yang berarti bahwa dari keenam indikator kemampuan komunikasi matematis siswa sesuai dengan perolehan angket yang paling banyak siswa lakukan dalam kegiatan pembelajaran pada materi persamaan linear satu variabel.

\section{KESIMPULAN}

Berdasarkan hasil penelitian dan pembahasan Kemampuan Komunikasi Matematis Siswa Terhadap Materi Persamaan Linear Satu Variabel Kelas VII Di SMP N 3 Sungai Tebelian Tahun Pelajaran 2021/2022 maka dapat disimpulkan bahwa:

1. Kemampuan komunikasi matematis siswa terhadap materi persamaan linear satu variabel pada kelas VII B SMP N 3 Sungai Tebelian yaitu: sikap terbuka siswa sudah terungkap berdasarkan hasil wawancara yang diperoleh peneliti. Hal ini berdasarkan hasil peolehan angket kemampuan komunikasi matematis dengan presentase tertinggi perolehan angket kemampuan komunikasi matematis siswa pada tabel 4.3 yaitu pada indikator mengungkapkan ide matematika secara lisan dan tulisan $3,5 \%$.

2. Kemampuan komunikasi matematis siswa terhadap materi persamaan linear satu variabel pada kelas VII B SMP N 3 Sungai Tebelian yaitu: hasil presentase indikator di atas diketahui bahwa sebagian besar siswa telah menunjukkan komunikasi matematis dalam pembelajaran matematika. Hal ini terlihat dari presentase tertinggi nilai hasil angket siswa yaitu sebesar 2,83\% dengan kategori baik yang diperoleh oleh Yensella dengan perolehan 6 point $\mathrm{Y}(+), 2$ point $\mathrm{Y}(-), 4$ point $\mathrm{T}(+)$ dan 0 $\mathrm{T}(-)$.

\section{DAFTAR PUSTAKA}

Hastuti, E. S., Eclarin, L., \& Dalam, K. K. S. (2021). Kecemasan Siswa Sekolah Menengah Pertama Menyelesaikan Masalah SPLDV Pada Kelas Virtual Dalam. International Journal of Progressive Mathematics Education, 1(1), 64-84. https://doi.org/10.22236/ijopme.v1i1.6914

Kosiret, A., Indiyah, F. H., \& Wijayanti, D. A. (2021). The Use of Generative Learning Model in Improving Students' Understanding of Mathematical Concepts of Al-Azhar 19 Islamic High School. International Journal of Progressive Mathematics Education, 1(1), 1626. https://doi.org/10.22236/ijopme.v1i1.6593

Ku, K. Y. L. (2009). Assessing students' critical thinking performance: Urging for measurements using multi-response format. Thinking Skills and Creativity, 4(1), 7076. https://doi.org/10.1016/j.tsc.2009.02.001 
Maulidiya, D., Susanta, A., \& Irsal, N. A. (2018). Model Investigasi Berbantuan Geogebra pada Geometri Bidang Abstrak. Jurnal Riset Pendidikan Matematika Jakarta, 1(2013), 1521. http://journal.unj.ac.id/unj/index.php/jrpmj/article/view/4969/3664

Mulligan, J. (2015). Looking within and beyond the geometry curriculum: connecting spatial reasoning to mathematics learning. ZDM Mathematics Education, 47(3), 511517. https://doi.org/10.1007/s11858-015-0696-1

NCTM. (2000). A Vision for School Mathematics. Principles and Standards for School Mathematics, 3-8.

Octaviani, K. D., Indrawatiningsih, N., \& Afifah, A. (2021). Kemampuan Visualisasi Spasial Siswa Dalam Memecahkan Masalah Geometri Bangun Ruang Sisi Datar Kemampuan Visualisasi Spasial Siswa Dalam Memecahkan Masalah Geometri Bangun Ruang Sisi Datar. International Journal of Progressive Mathematics Education, 1(1), 2740. https://doi.org/10.22236/ijopme.v1i1.6583

Paridjo, \& Waluya, S. B. (2017). Analysis Mathematical Communication Skills Students In The Matter Algebra Based Nctm. IOSR Journal of Mathematics, 13(I), 60-

66. https://doi.org/10.9790/5728-1301056066

Radford, L. (2008). Connecting theories in mathematics education: challenges and possibilities. ZDM - Mathematics Education, 40(2), 317-327. https://doi.org/10.1007/s11858-008-0090-3

Rahmi, A. (2021). Tahap Preliminary Research Pengembangan Media Pembelajaran Berbasis Komputer pada Materi Transformasi SMA / MA. Jurnal Riset Pendidikan Matematika Jakarta, 3(1), 14-18.

Rellensmann, J., Schukajlow, S., \& Leopold, C. (2017). Make a drawing. Effects of strategic knowledge, drawing accuracy, and type of drawing on students' mathematical modelling performance. Educational Studies in Mathematics, 95(1), 5378. https://doi.org/10.1007/s10649-016-9736-1

Samo, D. D. (2017). Kemampuan pemecahan masalah matematika mahasiswa tahun pertama dalam memecahkan masalah geometri konteks budaya. Jurnal Riset Pendidikan Matematika, 4(2), 141. https://doi.org/10.21831/jrpm.v4i2.13470

Sommerhoff, D., \& Ufer, S. (2019). Acceptance criteria for validating mathematical proofs used by school students, university students, and mathematicians in the context of teaching. ZDM Mathematics Education, 0(0), 0. https://doi.org/10.1007/s11858-019-01039-7

Sriraman, B., \& English, L. D. (2005). Theories of Mathematics Education: A global survey of theoretical frameworks/trends in mathematics education research. Zdm, 37(6), 450456. https://doi.org/10.1007/BF02655853

Susanti, E., \& Hartono. (2019). Mathematical critical thinking and creative thinking skills: How does their relationship influence mathematical achievement? ACM International Conference Proceeding Series, 63-66. https://doi.org/10.1145/3348400.3348408

Winardi, M. P. A., Halini, \& Hamdani. (2019). Hubungan Kecemasan Matematika Dan Kemampuan Komunikasi Matematis Siswa Kelas IX Pada Materi SPLDV. Jurnal Pendidikan Dan Pembelajaran Khatulistiwa, 8(3).

How to cite : Sopia, N., \& Kurniawati, 2021. Kemampuan Komunikasi Matematis Siswa Terhadap Materi Persamaan Linear Satu Variabel. Jurnal Riset Pendidikan Matematika Jakarta. 3(2). 1-7. https://doi.org/10.21009/jrpmj.v3i2.22261

To link to this article: https://doi.org/10.21009/jrpmj.v3i2.22261 